\title{
SDH Complex Gene Mutation
}

National Cancer Institute

\section{Source}

National Cancer Institute. SDH Complex Gene Mutation. NCI Thesaurus. Code C48301.

A change in the nucleotide sequence of any gene that encodes one of the proteins in the succinate dehydrogenase (SDH) complex. 